\title{
Oxidative stress and the use of antioxidants in diabetes: Linking basic science to clinical practice
} Jeanette Schultz Johansen ${ }^{\dagger 1}$, Alex K Harris ${ }^{\dagger 2}$, David J Rychly ${ }^{2}$ and Adviye Ergul*2,3

\author{
Address: ${ }^{1}$ University of Tromso, Tromso, Norway, ${ }^{2}$ University of Georgia College of Pharmacy, Athens, Georgia, USA and ${ }^{3}$ Medical College of \\ Georgia Vascular Biology Center, Augusta, Georgia, USA \\ Email: Jeanette Schultz Johansen - jeajoh@student.uit.no; Alex K Harris - aharris@mail.mcg.edu; David J Rychly - rychlyd@rx.uga.edu; \\ Adviye Ergul* - aergul@mail.mcg.edu \\ * Corresponding author †Equal contributors
}

Published: 29 April 2005

Cardiovascular Diabetology 2005, 4:5 doi:10.1186/1475-2840-4-5

This article is available from: http://www.cardiab.com/content/4/l/5

(C) 2005 Johansen et al; licensee BioMed Central Ltd.

This is an Open Access article distributed under the terms of the Creative Commons Attribution License (http://creativecommons.org/licenses/by/2.0), which permits unrestricted use, distribution, and reproduction in any medium, provided the original work is properly cited.
Received: 09 March 2005

Accepted: 29 April 2005

\begin{abstract}
Cardiovascular complications, characterized by endothelial dysfunction and accelerated atherosclerosis, are the leading cause of morbidity and mortality associated with diabetes. There is growing evidence that excess generation of highly reactive free radicals, largely due to hyperglycemia, causes oxidative stress, which further exacerbates the development and progression of diabetes and its complications. Overproduction and/or insufficient removal of these free radicals result in vascular dysfunction, damage to cellular proteins, membrane lipids and nucleic acids. Despite overwhelming evidence on the damaging consequences of oxidative stress and its role in experimental diabetes, large scale clinical trials with classic antioxidants failed to demonstrate any benefit for diabetic patients. As our understanding of the mechanisms of free radical generation evolves, it is becoming clear that rather than merely scavenging reactive radicals, a more comprehensive approach aimed at preventing the generation of these reactive species as well as scavenging may prove more beneficial. Therefore, new strategies with classic as well as new antioxidants should be implemented in the treatment of diabetes.
\end{abstract}

\section{Introduction}

It is a well-established fact that diabetes is a risk factor for cardiovascular disease $[1,2]$. While microvascular complications of diabetes include nephropathy and retinopathy, macrovascular complications resulting in atherosclerotic cardiovascular disease such as coronary artery disease, cerebrovascular disease and peripheral vascular disease are the leading cause of death in the diabetic population $[3,4]$. The Diabetes Control and Complications trial (DCCT) demonstrated that tight control of blood glucose is effective in reducing clinical complications significantly, but even optimal control of blood glucose could not prevent complications suggesting that alternative treatment strategies are needed [4]. Since numerous studies demonstrated that oxidative stress, mediated mainly by hyperglycemia-induced generation of free radicals, contributes to the development and progression of diabetes and related contributions, it became clear that ameliorating oxidative stress through treatment with antioxidants might be an effective strategy for reducing 
diabetic complications. To this end, several clinical trials investigated the effect of the antioxidant vitamin $\mathrm{E}$ on the prevention of diabetic complications. However, these trials failed to demonstrate relevant clinical benefits of this antioxidant on cardiovascular disease [5-7]. The negative results of the clinical trials with antioxidants prompted new studies focusing on the mechanisms of oxidative stress in diabetes in order to develop causal antioxidant therapy. In this article, sources of free radicals contributing to oxidative stress and the natural defense mechanisms in diabetes are briefly reviewed. Experimental and clinical evidence with respect to the use of conventional antioxidants in diabetes is summarized and causal therapy approaches with novel antioxidants are discussed.

\section{What is oxidative stress?}

Oxidative stress is defined in general as excess formation and/or insufficient removal of highly reactive molecules such as reactive oxygen species (ROS) and reactive nitrogen species (RNS) $[8,9]$. ROS include free radicals such as superoxide $\left(\bullet^{\circ} \mathrm{O}_{2}^{-}\right)$, hydroxyl $(\cdot \mathrm{OH})$, peroxyl $\left(\bullet^{\mathrm{RO}_{2}}\right)$, hydroperoxyl $\left(\cdot \mathrm{HRO}_{2}\right)$ as well as nonradical species such as hydrogen peroxide $\left(\mathrm{H}_{2} \mathrm{O}_{2}\right)$ and hydrochlorous acid (HOCl) $[8,10]$. RNS include free radicals like nitric oxide $(\bullet \mathrm{NO})$ and nitrogen dioxide $\left(\cdot \mathrm{NO}_{2}{ }^{-}\right)$, as well as nonradicals such as peroxynitrite (ONOO-), nitrous oxide $\left(\mathrm{HNO}_{2}\right)$ and alkyl peroxynitrates (RONOO) $[8,10]$. Of these reactive molecules, ${ }^{\bullet} \mathrm{O}_{2}{ }^{-},{ }^{\bullet} \mathrm{NO}$ and $\mathrm{ONOO}^{-}$are the most widely studied species and play important roles in the diabetic cardiovascular complications. Thus, these species will be discussed in more detail.

- NO is normally produced from L-arginine by endothelial nitric oxide synthase (eNOS) in the vasculature [8]. ${ }^{\bullet} \mathrm{NO}$ mediates endothelium-dependent vasorelaxation by its action on guanylate cyclase in vascular smooth muscle cells (VSMC), initiating a cascade that leads to vasorelaxation. $\cdot \mathrm{NO}$ also displays antiproliferative properties and inhibits platelet and leukocyte adhesion to vascular endothelium [8]. Therefore, $\bullet \mathrm{NO}$ is considered a vasculoprotective molecule. However, $\cdot \mathrm{NO}$ easily reacts with superoxide, generating the highly reactive molecule $\mathrm{ONOO}^{-}$, and triggering a cascade of harmful events as discussed below $[8,11]$. Therefore its chemical environment, i.e. presence of $\bullet^{\bullet} \mathrm{O}_{2}^{-}$, determines whether ${ }^{\bullet} \mathrm{NO}$ exerts protective or harmful effects.

Production of one ROS or RNS may lead to the production of others through radical chain reactions. As summarized in Fig. $1^{\bullet}{ }^{\bullet} \mathrm{O}_{2}$-is produced by one electron reduction of oxygen by several different oxidases including $\mathrm{NAD}(\mathrm{P}) \mathrm{H}$ oxidase, xanthine oxidase, cyclooxygenase and even eNOS under certain conditions as well as by the mitochondrial electron transport chain during the course of normal oxidative phosphorylation, which is essential for generating ATP [12-15]. Under normal conditions, - $\mathrm{O}_{2}$ - is quickly eliminated by antioxidant defense mechanisms. ${ }^{\circ} \mathrm{O}_{2}{ }^{-}$is dismutated to $\mathrm{H}_{2} \mathrm{O}_{2}$ by manganese superoxide dismutase (Mn-SOD) in the mitochondria and by copper $(\mathrm{Cu})$-SOD in the cytosol [12]. $\mathrm{H}_{2} \mathrm{O}_{2}$ is converted to $\mathrm{H}_{2} \mathrm{O}$ and $\mathrm{O}_{2}$ by glutathione peroxidase (GSH-Px) or catalase in the mitochondria and lysosomes, respectively. $\mathrm{H}_{2} \mathrm{O}_{2}$ can also be converted to the highly reactive ${ }^{\bullet} \mathrm{OH}$ radical in the presence of transition elements like iron and copper.

\section{Why are reactive species bad?}

While ROS are generated under physiological conditions and are involved to some extent as signaling molecules and defense mechanisms as seen in phagocytosis, neutrophil function, and shear-stress induced vasorelaxation, excess generation in oxidative stress has pathological consequences including damage to proteins, lipids and DNA. These detrimental effects are briefly summarized in this section.

ROS can stimulate oxidation of low-density lipoprotein (LDL), and ox-LDL, which is not recognized by the LDL receptor, can be taken up by scavenger receptors in macrophages leading to foam cell formation and atherosclerotic plaques [16]. As will be discussed in greater detail in the next section, ${ }^{\bullet} \mathrm{O}_{2}{ }^{-}$can activate several damaging pathways in diabetes including accelerated formation of advanced glycation end products (AGE), polyol pathway, hexosamine pathway and PKC, all of which have been proven to be involved in micro- and macrovascular complications. ${ }^{\cdot} \mathrm{O}_{2}$ - and $\mathrm{H}_{2} \mathrm{O}_{2}$ stimulate stress-related signaling mechanisms such as NF- $\mathrm{KB}, \mathrm{p} 38$-MAPK and STAT-JAK resulting in VSMC migration and proliferation. In endothelial cells, $\mathrm{H}_{2} \mathrm{O}_{2}$ mediates apoptosis and pathological angiogenesis [15]. Furthermore, $\bullet^{-} \mathrm{O}_{2}$ - immediately reacts with ' $\mathrm{NO}$ generating cytotoxic $\mathrm{ONOO}^{-}$and this reaction itself has several consequences. First, ONOOalters function of biomolecules by protein nitration as well as causing lipid peroxidation [8]. For example, potassium channels, which regulate the vasorelaxation response, are inhibited by nitration $[17,18]$. As recently reviewed by Turko et al, increased levels of nitrotyrosine are associated with apoptosis of myocytes, endothelial cells and fibroblasts in diabetes [8]. Second, ONOOcauses single-strand DNA breakage which in turn activates nuclear enzyme poly(ADP-ribose) polymerase (PARP) [19]. Third, it decreases $\cdot N O$ bioavailability causing impaired relaxation and inhibition of the antiproliferative effects of $\bullet \mathrm{NO}$ [9]. Furthermore, ONOO- oxidizes tetrahydrobiopterin $\left(\mathrm{BH}_{4}\right)$, an important cofactor for NOS, and causes uncoupling of NOS, which produces ${ }^{\circ} \mathrm{O}_{2}$ - instead of $\bullet \mathrm{NO}$ [9]. ROS-induced peroxidation of membrane lipids alters the structure and the fluidity of biological membranes, which ultimately affects function [9,13-15]. All 


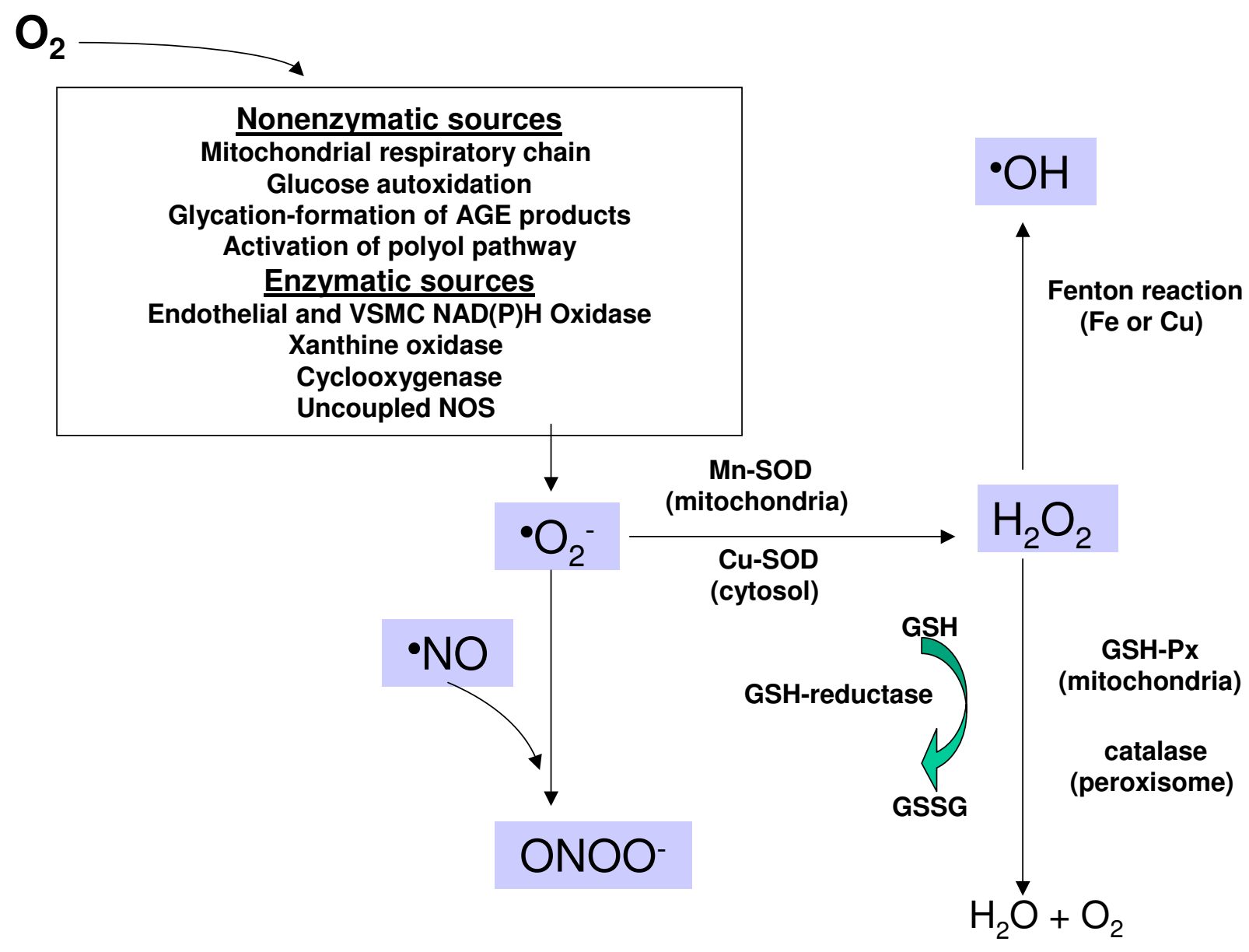

Figure I

Generation of reactive species in diabetes. Highlighted in gray are some of the most important ROS and RNS in vascular cells. Oxygen is converted to ${ }^{\circ} \mathrm{O}_{2}$ - via the activation of enzymatic and nonenzymatic pathways, which is then dismutated to $\mathrm{H}_{2} \mathrm{O}_{2}$ by SOD. $\mathrm{H}_{2} \mathrm{O}_{2}$ can be converted to $\mathrm{H}_{2} \mathrm{O}$ by catalase or glutathione peroxidase (GSH-Px) or to ${ }^{\circ} \mathrm{OH}$ after reaction with $\mathrm{Cu}$ or Fe. Glutathione reductase regenerates glutathione (GSH). In addition, ${ }^{\circ} \mathrm{O}_{2}^{-}$reacts rapidly with ' $\mathrm{NO}$ to form $\mathrm{ONOO}$.

these pathological modifications contribute to the pathogenesis of vascular dysfunction.

\section{Sources of oxidative stress in diabetes}

Direct evidence of oxidative stress in diabetes is based on studies that focused on the measurement of oxidative stress markers such as plasma and urinary $\mathrm{F}_{2}$-isoprostane as well as plasma and tissue levels of nitrotyrosine and ${ }^{-} \mathrm{O}_{2}{ }^{-}[11,20-23]$. There are multiple sources of oxidative stress in diabetes including nonenzymatic, enzymatic and mitochondrial pathways. Thus, we will first discuss these mechanisms and conclude with the recently proposed working plan for the initiation of oxidative stress and related vascular complications in diabetes.
Nonenzymatic sources of oxidative stress originate from the oxidative biochemistry of glucose. Hyperglycemia can directly cause increased ROS generation. Glucose can undergo autoxidation and generate ${ }^{\bullet} \mathrm{OH}$ radicals [8]. In addition, glucose reacts with proteins in a nonenzymatic manner leading to the development of Amadori products followed by formation of AGEs. ROS is generated at multiple steps during this process. In hyperglycemia, there is enhanced metabolism of glucose through the polyol (sorbitol) pathway, which also results in enhanced production of ${ }^{\bullet} \mathrm{O}_{2}{ }^{-}$.

Enzymatic sources of augmented generation of reactive species in diabetes include NOS, NAD $(\mathrm{P}) \mathrm{H}$ oxidase and 
xanthine oxidase $[21,22,24]$. All isoforms of NOS require five cofactors/prosthetic groups such as flavin adenine dinucleotide (FAD), flavin mononucleotide (FMN), heme, $\mathrm{BH}_{4}$ and $\mathrm{Ca}^{2+}$-calmodulin. If NOS lacks its substrate L-arginine or one of its cofactors, NOS may produce - $\mathrm{O}_{2}$ - instead of $\bullet \mathrm{NO}$ and this is referred to as the uncoupled state of NOS $[9,21,22,24]$. NAD $(\mathrm{P}) \mathrm{H}$ oxidase is a membrane associated enzyme that consists of five subunits and is a major source of ${ }^{\circ} \mathrm{O}_{2}$ - production $[21,22,25,26]$. Guzik et al. investigated $\bullet^{\bullet} \mathrm{O}_{2}$ - levels in vascular specimens from diabetic patients and probed sources of ${ }^{\bullet} \mathrm{O}_{2}-$ using inhibitors of NOS, NAD(P)H oxidase, xanthine oxidase and mitochondrial electron transport chain. This study demonstrated that there is enhanced production of $\bullet^{-} \mathrm{O}_{2}$ - in diabetes and this is predominantly mediated by NAD(P)H oxidase. Furthermore, the NOS-mediated component is greater in patients with diabetes than in patients who do not have diabetes [22]. We have also observed that $\mathrm{NAD}(\mathrm{P}) \mathrm{H}$ oxidase activity is significantly higher in vascular tissue (saphenous vein and internal mammary artery) obtained from diabetic patients [27]. There is plausible evidence that PKC, which is stimulated in diabetes via multiple mechanisms, i.e. polyol pathway and Ang II, activates NAD(P)H oxidase [28].

The mitochondrial respiratory chain is another source of nonenzymatic generation of reactive species. During the oxidative phosphorylation process, electrons are transferred from electron carriers NADH and $\mathrm{FADH}_{2}$, through four complexes in the inner mitochondrial membrane, to oxygen, generating ATP in the process [29]. Under normal conditions, $\bullet^{-} \mathrm{O}_{2}$ - is immediately eliminated by natural defense mechanisms. A recent study demonstrated that hyperglycemia-induced generation of ${ }^{\cdot} \mathrm{O}_{2}{ }^{-}$at the mitochondrial level is the initial trigger of vicious cycle of oxidative stress in diabetes [30,31]. When endothelial cells are exposed to hyperglycemia at the levels relevant to clinical diabetes, there is increased generation of ROS and especially $\bullet^{\circ} \mathrm{O}_{2}$, which precedes the activation of four major pathways involved in the development of diabetic complications. Nishikawa and colleagues elegantly demonstrated that generation of excess pyruvate via accelerated glycolysis under hyperglycemic conditions floods the mitochondria and causes ${ }^{-} \mathrm{O}_{2}$ - generation at the level of Complex II in the respiratory chain. What is more important is that blockade of $\boldsymbol{O}_{2}$ - radicals by three different approaches using either a small molecule uncoupler of mitochondrial oxidative phosphorylation (CCCP), overexpression of uncoupling protein-1 (UCP1) or overexpression of $\mathrm{Mn}-\mathrm{SOD}$, prevented changes in NF- $\mathrm{KB}$ as well as polyol pathway, AGE formation and PKC activity. Based on this information, it has been postulated by several groups that mitochondrial ${ }^{\bullet} \mathrm{O}_{2}$ - is the initiating snowball that turns oxidative stress into an avalanche in diabetes by stimulating more ROS and RNS production via downstream activation of NF-KB-mediated cytokine production, PKC and NAD(P)H oxidase (Fig. 2). Thus, inhibition of intracellular free radical formation would provide a causal therapy approach in the prevention of oxidative stress and related vascular complications in diabetes.

\section{Natural defense against oxidative stress and antioxidants}

Reactive species can be eliminated by a number of enzymatic and nonenzymatic antioxidant mechanisms. As discussed above, SOD immediately converts ${ }^{\circ} \mathrm{O}_{2}{ }^{-}$to $\mathrm{H}_{2} \mathrm{O}_{2}$, which is then detoxified to water either by catalase in the lysosomes or by glutathione peroxidase in the mitochondria (Fig. 1). Another enzyme that is important is glutathione reductase, which regenerates glutathione that is used as a hydrogen donor by glutathione peroxidase during the elimination of $\mathrm{H}_{2} \mathrm{O}_{2}$. Maritim and colleagues recently reviewed in detail that diabetes has multiple effects on the protein levels and activity of these enzymes, which further augment oxidative stress by causing a suppressed defense response [9]. For example, in the heart, which is an important target in diabetes and prone to diabetic cardiomyopathy leading to chronic heart failure, SOD and glutathione peroxidase expression as well as activity are decreased whereas catalase is increased in experimental models of diabetes $[9,32,33]$. In patients with chronic heart failure, all three enzymes are decreased in the smooth muscle [34] and exercise training can upregulate the expression and activity of antioxidant enzymes. Increased isoprostane levels in diabetic patients with chronic heart failure are correlated with antioxidant status and disease severity [35]. Thus, modulation of these enzymes in target organs prone to diabetic complications such as heart and kidney may prove beneficial in the prevention and management of heart failure and kidney failure.

Nonenzymatic antioxidants include vitamins $\mathrm{A}, \mathrm{C}$ and $\mathrm{E}$; glutathione; $\alpha$-lipoic acid; carotenoids; trace elements like copper, zinc and selenium; coenzyme $\mathrm{Q}_{10}\left(\mathrm{CoQ}_{10}\right)$; and cofactors like folic acid, uric acid, albumin, and vitamins $\mathrm{B}_{1}, \mathrm{~B}_{2}, \mathrm{~B}_{6}$ and $\mathrm{B}_{12}$. Alterations in the antioxidant defense system in diabetes have recently been reviewed [11]. Glutathione (GSH) acts as a direct scavenger as well as a cosubstrate for GSH peroxidase. It is a major intracellular redox tampon system. Vitamin $\mathrm{E}$ is a fat-soluble vitamin that prevents lipid peroxidation. It exists in 8 different forms, of which $\alpha$-tocopherol is the most active form in humans. Hydroxyl radical reacts with tocopherol forming a stabilized phenolic radical which is reduced back to the phenol by ascorbate and NAD $(\mathrm{P}) \mathrm{H}$ dependent reductase enzymes [36,37]. $\mathrm{CoQ}_{10}$ is an endogenously synthesized compound that acts as an electron carrier in the Complex II of the mitochondrial electron transport chain. Brownlee et al reported that this is the site of ${ }^{\bullet} \mathrm{O}_{2}$ - generation under hyperglycemic conditions [30,31]. $\mathrm{CoQ}_{10}$ is a lipid 


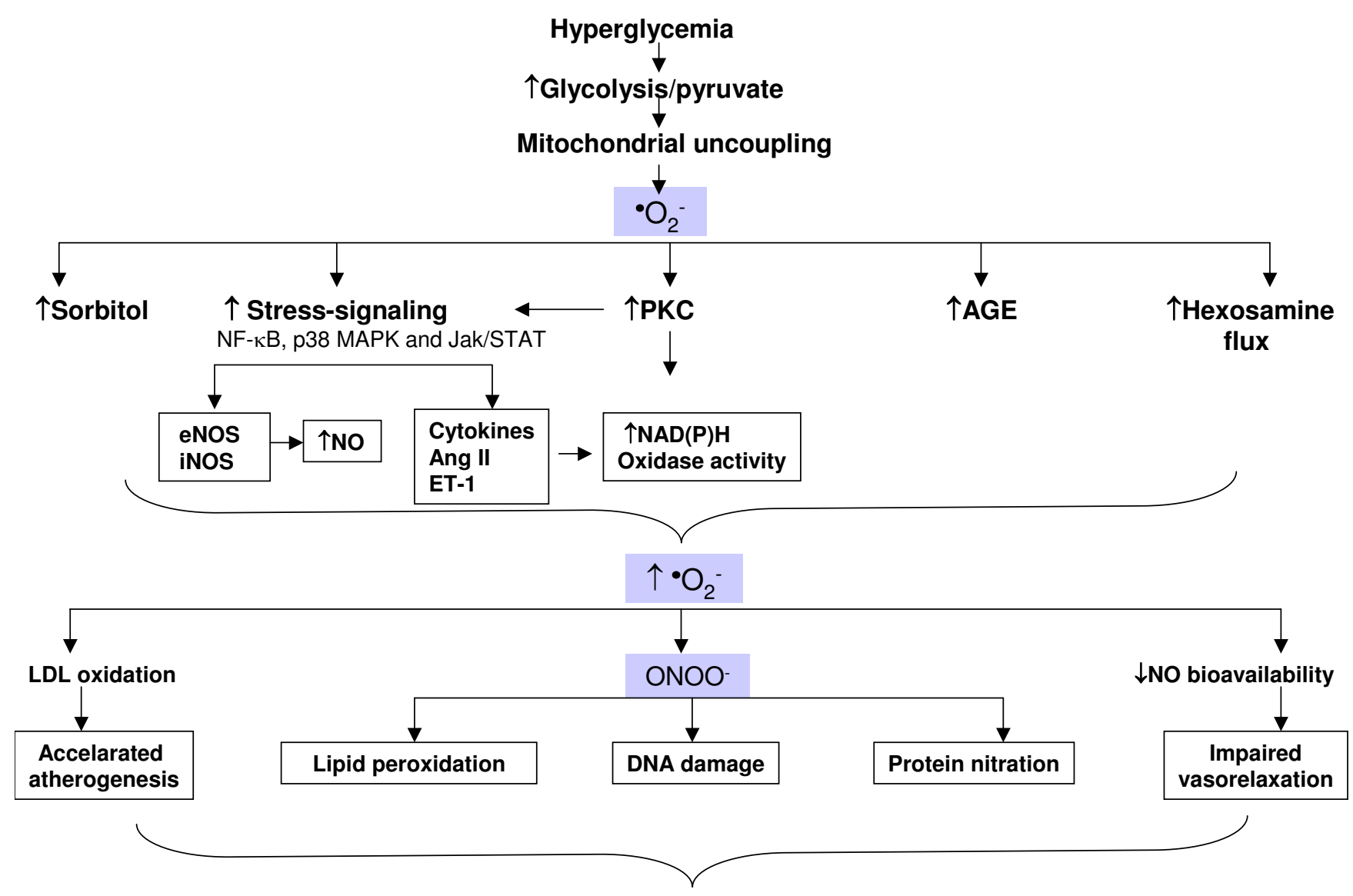

\section{DIABETIC VASCULAR DISEASE}

Figure 2

Current working model for the generation of reactive species and downstream targets in diabetes. Excess generation of mitochondrial ROS due to hyperglycemia initiates a vicious circle by activating stress-sensitive pathways such as NFKB, p38 MAPK and Jak/STAT, polyol (sorbitol) and hexosamine pathways, PKC and AGEs. Enhanced production of AGEs, sorbitol and proinflammatory cytokines exerts a positive feedback on ROS and RNS synthesis and potentiates PKC-mediated vascular dysfunction by altering gene expression as well as vascular function and structure.

soluble antioxidant, and in higher concentrations, it scavenges ${ }^{\bullet} \mathrm{O}_{2}$ - and improves endothelial dysfunction in diabetes [38-40]. Vitamin C (ascorbic acid) increases NO production in endothelial cells by stabilizing NOS cofactor $\mathrm{BH}_{4}[41]$. $\alpha$-Lipoic acid is a hydrophilic antioxidant and can therefore exert beneficial effects in both aqueous and lipid environments. $\alpha$-lipoic acid is reduced to another active compound dihydrolipoate. Dihydrolipoate is able to regenerate other antioxidants such as vitamin $\mathrm{C}$, vitamin $\mathrm{E}$ and reduced glutathione through redox cycling [41]. Thus, both experimental and clinical studies summarized in the next sections utilized these naturally occurring antioxidants, especially vitamins C, E and $\alpha$-lipoic acid, in order to delineate the role of oxidative stress in the development of vascular complications of diabetes.

\section{Evidence from experimental models}

A multitude of in vivo studies have been performed utilizing antioxidants in experimental diabetic models. The effects of antioxidants on oxidative stress are measured through certain observable biomarkers. These markers include the enzymatic activities of catalase, SOD, GSH-Px, and GSH-reductase, as well as thiobarbituric acid reactants (TBARS) levels, an indirect measurement of free-radical production that has been shown to be consistently elevated in diabetes. Normalization of the activity levels 
of any of these markers, and ultimately, the balance of free-radical production/removal, would be an effective method to reduce ROS-induced damage. Many animal studies have been completed with this aim in mind and indeed have shown that diabetes-induced alterations of oxidative stress indicators can be reversed when the animals are treated with various antioxidants. It should be noted that a plethora of studies have been done with numerous antioxidant compounds. We will, however, only cover a select few within the scope of this review, specifically the compounds for which a corresponding human clinical trial has been conducted

Mekinova et al. demonstrated that supplementation of streptozotocin (STZ) diabetic rats with vitamins C, E, and beta-carotene for 8 weeks produced a significant reduction of TBARS levels, GHS, and GHS-Px, an increase in CuSOD, and no change in catalase activity in kidneys [42]. Treatment with vitamins $\mathrm{C}$ and $\mathrm{E}$ was also shown to decrease urinary albumin excretion, glomerular basement membrane thickness, and kidney weight in STZ diabetic rats [43]. In the same study, vitamins $C$ and E significantly lowered malondialdehyde (TBARS) levels and GSH-Px activity while increasing catalase and SOD activities when compared to unsupplemented diabetic animals [43]. A study by Cinar et el. demonstrated that supplementation with vitamin E significantly lowered liver and lung TBARS levels and improved impaired endothelium-dependent vasorelaxation in STZ diabetic rat aorta [44].

$\alpha$-lipoic acid, which is involved in mitochondrial dehydrogenase reactions, has gained a considerable amount of attention as an antioxidant. Studies have demonstrated that intraperitoneal administration of $\alpha$-lipoic acid to STZ diabetic Wistar rats normalizes TBARS level in plasma, retina, liver, and pancreas [45]. In the same study, Obrosova et.al observed a reduction of GSH activity in diabetic retina and that supplementation with $\alpha$-lipoic acid produced no change [45]. However, another study demonstrated an increase in aortic GSH-Px in STZ diabetic rats that was normalized by treatment with $\alpha$-lipoic acid [46]. Additionally, increased maximum contractile responses in diabetic aortic rings were ameliorated with $\alpha$-lipoic acid treatment [46].

SOD activity is undoubtedly important to the regulation of oxidative status in diabetes. However, there is variation as to the status of this enzyme in the diabetic state. Some studies have reported decreased SOD activity $[43,45]$ while others have shown increases [47] or no change in the enzyme $[42,48]$. $\alpha$-lipoic acid has been observed to normalize diabetes-induced decreases of SOD in rat heart [48] and retina [45]. One study demonstrated that treatment of STZ diabetic rats with $\alpha$-lipoic acid reverses SODinduced vasorelaxation, potentially due to the elimina- tion of excess superoxide/hydrogen peroxide and the recovery of basal NO [46]. A recent study by Brands et al. investigated the effect of oxidative stress in the development of hypertension in diabetes using the SOD mimetic tempol in a Type 1 model of diabetes where NOS is pharmacologically inhibited with a NOS inhibitor, L-NAME [49]. In this model, hyperglycemia causes hypertension implicating an important role for NO. Results of this study showed that if ${ }^{\bullet} \mathrm{O}_{2}$ - is eliminated by tempol early in the disease process, the hypertension and decrease in glomerular filtration precipitated by diabetes are prevented.

In summary, there are differences in response to antioxidants in experimental diabetes in the prevention of cardiovascular complications. Studies in experimental models provide a foundation for the clinical studies but results should be interpreted cautiously since the experimental models of diabetes, duration and type of antioxidant treatment and markers of oxidative stress investigated in these studies exhibit a wide range.

\section{Evidence from clinical trials}

Although studies with antioxidants in experimental models as well as observational studies strongly suggest that antioxidants should confer beneficial effects in reducing cardiovascular complications in diabetes, clinical evidence for the use of antioxidants is not solid. It should be emphasized that clinical trials with antioxidants in diabetes are limited and majority of these trials focused on the use of vitamin $\mathrm{E}$ and $\mathrm{C}$ and lately $\alpha$-lipoic acid. Thus, we will attempt to group the clinical trials by the antioxidants used.

Small trials with vitamin E demonstrated beneficial cardiovascular effects. In a double-blind, placebo-controlled, randomized study, vitamin E supplementation (1000 IU/ day) for three months in patients with Type 1 diabetes ( $\mathrm{n}$ $=41$ ) significantly improved endothelium-dependent vasorelaxation [50]. In another study, Beckman et al. reported that administration of vitamin E ( $800 \mathrm{IU} /$ day) and C (1000 mg/day) combination for six months had a positive effect on endothelium-dependent vasorelaxation in Type 1 diabetic patients $(n=26)$ but had no effect in Type 2 diabetes $(n=23)$ [51]. Gaede et al reported that vitamin $\mathrm{E}(680 \mathrm{mg} /$ day $)$ and $\mathrm{C}(1250 \mathrm{mg} /$ day $)$ combination significantly improved renal function in Type 2 diabetes [52].

Other clinical trials on a larger scale include the Heart Outcomes Prevention Evaluation (HOPE) trial [53], Secondary Prevention with Antioxidants of Cardiovascular Disease in End Stage Renal Disease (SPACE) trial [54], the Steno trial [55], the Primary Prevention Project (PPP) trial [56] and the Study to Evaluate Carotid Ultrasound 
Changes in Patients Treated With Ramipril and Vitamin E (SECURE) trial [57].

The HOPE trial enrolled patients 55 years of age or older who were at high risk for cardiovascular disease and recruited significant number of patients with diabetes. This study had a $2 \times 2$ factorial design where in one arm patients were randomized to vitamin E (400 IU/day) or placebo and in the other arm of the study patients were randomized to ramipril $(10 \mathrm{mg} /$ day $)$ or placebo [53]. Results with vitamin E and ramipril were evaluated separately as compared to respective placebo groups. In the vitamin E arm, 4761 patients received vitamin E and 4780 patients were given placebo. In the treatment and placebo groups, the number of patients with diabetes was 1838 and 1816 , respectively. The primary endpoint was a composite of myocardial infarction, stroke and death from cardiovascular causes. The trial was stopped for ethical reasons after 4.5 years follow-up by the recommendations of an independent data and safety monitoring board based on the beneficial effects of ramipril on cardiovascular events in the concurrent treatment group and lack of effect in the vitamin E treatment group. Results of the study were published in 2000 and demonstrated that there was no significant difference in the primary outcome between vitamin E and placebo groups [53]. Analyses of the secondary endpoints of the study, which included total mortality, hospitalizations for heart failure and unstable angina, revascularization and nephropathy, were recently published [58], and again vitamin E supplementation for 4.5 years failed to provide any benefit in cardiovascular outcomes or nephropathy. It was also reported that there were no significant adverse events associated with vitamin E. The HOPE trial was the largest trial conducted thus far for the use of antioxidants in diabetes. The SECURE trial was designed as a substudy of the HOPE trial to evaluate the effects of long-term treatment with ramipril and vitamin $\mathrm{E}$ on atherosclerosis progression in high-risk patients. In this trial, 732 patients who had vascular disease or diabetes were randomized to two doses of ( 2.5 or $10 \mathrm{mg} / \mathrm{d}$ ) ramipril and vitamin E (400 IU/ day) or placebo and progression of atherosclerosis was monitored by B-mode carotid ultrasound. While ramipril slowed down atherosclerotic changes, vitamin $\mathrm{E}$ had no effect as compared to placebo group.

The SPACE trial recruited 196 hemodialysis patients with preexisting cardiovascular disease who were assigned to either placebo $(n=99)$ or $800 \mathrm{IU} /$ day vitamin $\mathrm{E}(\mathrm{n}=97)$ for 2 years. $43 \%$ of the patients in each group had diabetes. The primary endpoint was a composite of myocardial infarction, stroke, peripheral arterial disease or unstable angina. There was a $46 \%$ decrease in the primary end point events in the vitamin E group and this was mainly due to a $70 \%$ reduction in total myocardial infarction
[54]. The PPP trial was a randomized trial again with a 2 $\times 2$ design to evaluate the effect of low dose aspirin (100 $\mathrm{mg} /$ day) and vitamin $\mathrm{E}(300 \mathrm{mg} /$ day $)$ on the prevention of cardiovascular complications in high-risk patients. Similar to the studies discussed above, the primary endpoint was a composite of cardiovascular death, stroke or myocardial infarction. Out of the 4784 patients recruited, 1031 had diabetes. The PPP trial was stopped prematurely by the recommendations of an independent data and safety monitoring board based on the consistent beneficial effects of aspirin as compared to placebo group. However, there was no significant effect of vitamin E treatment either in diabetic or nondiabetic subjects. Lastly, the Steno-2 trial compared the effect of a multifactorial intensive therapy $(\mathrm{n}=80)$ with that of conventional treatment $(\mathrm{n}=80)$ on modifiable risk factors for cardiovascular disease in patients with Type 2 diabetes [55]. In the intensive treatment group, patients received pharmacotherapy that targeted hyperglycemia, dyslipidemia, hypertension and microalbuminuria including daily supplementation of vitamin C (250 mg), E (100 mg), folic acid (400 mg) and chromium picolinate $(100 \mathrm{mg})$ as well as behavior modification including low-fat diet, exercise and smoking cessation. The control group received conventional therapy as recommended in national guidelines. The intensive therapy resulted in almost a 50\% decrease in the risk of cardiovascular events providing evidence that a multifactorial approach is superior to conventional therapy for the prevention of oxidative stress-induced vascular complications in diabetes.

Studies with $\alpha$-lipoic acid are approved for the treatment of diabetic neuropathy and results are more promising than those obtained with vitamin E. In the Alpha Lipoic Acid in Diabetic Neuropathy (ALADIN) study, infusion of $\alpha$-lipoic acid $(>600 \mathrm{mg}$ ) significantly improved patient symptoms [59]. The ALADIN II Study demonstrated that long-term (24 months) use of $\alpha$-lipoic acid (600 or 1200 $\mathrm{mg}$ ) improved nerve function [60]. ALADIN III, a randomized multicenter double-blind placebo controlled study, showed that in a cohort of 509 patients, $600 \mathrm{mg} \alpha$ lipoic acid administration for 6 months improved neuropathy impairment score as early as 19 days, which was maintained up to 7 months [61]. The DEKAN (Deutsche kardiale autonome neuropathie) study evaluated the effect of $800 \mathrm{mg} \alpha$-lipoic acid or placebo in diabetic patients with cardiac autonomic neuropathy for 4 months and showed that heart rate variability, an indicator of cardiac autonomic neuropathy, significantly improved with $\alpha$-lipoic acid treatment [62]. The SYDNEY trial investigated the effect of $\alpha$-lipoic acid treatment on sensory symptoms of diabetic polyneuropathy as assessed by the Total Symptom Score. Administration of this antioxidant over a 3-week period improved sensory symptoms such as pain, prickling and numbness [63]. A recent meta-analysis 
of trials with $\alpha$-lipoic acid concluded that treatment with intravenous $\alpha$-lipoic acid (600 mg/day) over a 3-week period is safe and effective in improving positive neuropathic symptoms as well as neuropathic deficits [64].

In summary, clinical trials with conventional antioxidants in diabetic patients are limited. For major cardiovascular outcomes, vitamin E failed to provide any benefit. However, when study population was limited to diabetic patients alone as done in diabetic neuropathy trials, $\alpha$ lipoic acid has proven to be effective. As further discussed under Perspectives, this antioxidant may be a viable option in trials focusing on cardiovascular outcomes in diabetes.

In addition to the many antioxidants examined above, a number of commonly used drugs have shown promising antioxidant activity in addition to their primary pharmacological activity. These drugs include thiazolidinediones (TZDs), HMG-CoA reductase inhibitors (statins), and inhibitors of the renin-angiotensin system.

Thiazolidinediones (TZDs) have been shown in many animal studies to have antioxidant effect. In one study, pioglitazone-treated rats had reduced urinary excretion of isoprostane, a marker of oxidative stress [65]. In a trial with type-2 diabetic rats, Bagi et al demonstrated that treatment with rosiglitazone reduced NAD $(\mathrm{P}) \mathrm{H}$-derived ROS and increased the activity of catalase [66]. Another study using type-2 diabetic rats found that treatment with troglitazone lowered hydroperoxides and decreased SOD activity [67]. A study using troglitazone and pioglitazone in type- 2 diabetic rats found that both agents reduced TBARS levels and increased the aortic vasorelaxation response [68].

There is substantial evidence from in vitro studies that statins exert an antioxidant effect. Studies have demonstrated that statin therapy markedly reduces oxidative stress markers (such as nitrated tyrosine) in animals [69]. Although the mechanisms for these actions are still being elucidated, Takayama et al have demonstrated in canine models that the antioxidant effect of statins is at least partially due to inhibition of NAD(P)H oxidase [70]. Statins have also been shown to stimulate the activity of the antioxidant enzyme thioredoxin [71]. Additionally, statin therapy has been shown to stimulate the activity of paraoxonase (PON), which has a putative role in protecting LDL from oxidation [72]. Oxidation of LDL ex vivo has been shown to be inhibited by long-term statin therapy, an effect thought to be partly due to the binding of the statins to the LDL itself. It seems likely from the above studies that the antioxidant actions of statins are manifested via a variety of mechanisms.
Inhibitors of Angiotensin II (Ang II) activity, such as Angiotensin Converting Enzyme Inhibitors (ACEIs) and Angiotensin II receptor blockers (ARBs) have shown some beneficial effects that may stem from their antioxidant properties. Angiotensin II has been shown to increase ROS levels in animal studies, through stimulation of NAD $(P) H$ oxidase activity $[15,73]$. Studies have suggested that this effect also occurs in humans $[73,74]$. Ang II has also been implicated in upregulating the expression of the LOX-1 receptor, which is specific for oxidized LDL cholesterol. Inhibition of the generation of Ang II, whether by ACEI or ARB, should therefore attenuate these deleterious processes. Indeed, Berry et al have shown that treatment with ACEI or ARB decreases ${ }^{\bullet} \mathrm{O}_{2}$ - levels in the human vasculature [75].

In summary, many of the agents which are a mainstay of pharmacotherapy in diabetes have been shown to have antioxidant properties in addition to their primary pharmacological actions. These antioxidant properties may be a contributing factor to the therapeutic efficacy of these agents. Their antioxidant properties make the case for use of these drugs even more compelling. Particularly in light of the lackluster results seen in clinical trials with antioxidant supplementation, health care providers should redouble their efforts to ensure adequate usage of the demonstrably effective agents summarized above.

\section{Perspectives- Is there a role for antioxidant treatment in diabetes?}

Although the clinical trials conducted to date failed to provide adequate support for the use of antioxidants in diabetes, it is still to early to reach a definitive conclusion on this issue. As discussed above, with the exception of alpha-lipoic acid studies in diabetic neuropathy, data from clinical trials are limited. The majority of studies were not designed to assess the effect of antioxidant use specifically in diabetic patients. This is an important point because diabetic patients represent a population in whom oxidative stress is much higher than in the general population. As was seen in the SPACE trial of patients on hemodialysis, patients exposed to very high oxidative stress responded favorably to vitamin E supplementation [54]. It is possible that antioxidants would be more demonstrably effective in a patient population chosen on the basis of elevated levels of oxidative stress. Unfortunately, none of the studies to date effectively assessed the baseline oxidative stress of the enrolled patients using any of the commonly accepted markers of inflammation.

The human trials to date used endpoints that were not directly related to oxidative stress, but rather gross markers of overall cardiovascular health, such as effect on mortality. The studies failed to assess the duration of the diabetic disease states, arguably a large confounding variable. In 
assessing oxidative stress and the effects of antioxidants thereon, specific markers of oxidative stress should be measured.

With respect to the specific antioxidants studied, their selection was based on epidemiological and observational data, and in the absence of any solid grasp of the underlying mechanisms of action. Whereas observational studies are based on whole populations and reflect the lifelong influence of dietary habits, most of the studies were five years duration or less and included older patients (average age 65.4 years). It is possible that the study populations represented patients in whom the disease states had progressed too far to be amenable to antioxidant intervention.

In all likelihood, the choice and dose of antioxidant might be very important. The clinical trials focused mainly on the use of vitamin E. Negative results with vitamins cannot be generalized to all antioxidants. As has been eloquently argued elsewhere, treating the antioxidant vitamins as a single class of compounds with expected similar effects inappropriately disregards their wide range of chemical properties and pharmacodynamics [76]. Clinical trials to date have been conducted without any real understanding of the mechanisms of action or the concentrations of the various agents seen at different physiological sites. Indeed, there is not sufficient evidence to demonstrate that vitamin $\mathrm{E}$ reaches target cells.

Recently, it has been postulated that antioxidant potency of vitamins such as $\mathrm{C}$ and $\mathrm{E}$ is limited because these antioxidants work as scavengers of existing excess reactive species in a stoichiometric manner and this approach represents a symptomatic approach to oxidative stressassociated clinical problems [77]. Based on the new developments in our understanding of the pathophysiology of oxidative stress, it is clear that strategies to block the formation of reactive radicals will provide a targeted and causal approach to provide conclusive evidence whether antioxidants should be part of the cardiovascular treatment plan in diabetes. Candidate agents include low molecular weight mitochondrial and cytosolic SOD and catalase mimetics, L-propionyl carnitine, PKC- $\beta$ inhibitor LY-333531, peroxynitrite catalyst FP15 and mitochondrial uncoupler DNP $[9,77,78]$.

Given the number of shortcomings in the clinical trials, it seems clear that more research on the use of antioxidants in the prevention of cardiovascular complications in diabetes is necessary and strongly encouraged. From a clinical viewpoint, however, efforts for the prevention of diabetic complications should seek to maximize the benefits of proven therapeutic strategies including appropri- ate life style changes and controlling blood pressure, blood glucose and lipids.

In conclusion, the amount of evidence on the harmful effects of oxidative stress on vascular function and the link to pathophysiological mechanisms underlying diabetic complications is compelling. While the lack of clinical evidence on the beneficial effects of antioxidant vitamins in diabetes management should not deter us from more basic and clinical research on this issue, practice guidelines that are based on the results of numerous clinical trials should be our guide to evidence-based medicine in the prevention of cardiovascular disease in diabetes. The recent American Heart Association science advisory on the subject of antioxidant vitamins and cardiovascular disease asserted that there is insufficient evidence to justify the use of antioxidant vitamins for cardiovascular disease risk reduction [79]. Hopefully, further research into the pathophysiology of oxidative stress and the role of antioxidant therapy will lead to appropriately-designed clinical trials in which the promise of antioxidant therapy will be realized.

\section{Competing Interests}

The author(s) declare that they have no competing interests.

\section{Authors' Contributions}

AKH and JSJ contribute equally to writing the evidencebased sections and drafting of this review. DR was responsible for critical revision and formatting. AE participated in all aspects and areas of this review.

\section{Acknowledgements}

This work was supported by grants from NIH (HL076236-0I), American Heart Association Scientist Development Grant and American Diabetes Association to Adviye Ergul and an AHA Southeast Affiliate Predoctoral Fellowship Award to Alex K. Harris.

\section{References}

I. Pyorala K, Laakso M, Uusitupa M: Diabetes and atherosclerosis: an epidemiologic view. Diabetes Metab Rev 1987, 3(2):463-524.

2. Laakso M: Hyperglycemia and cardiovascular disease in type 2 diabetes. Diabetes 1999, 48(5):937-942.

3. American Diabetes Association: National diabetes fact sheet. 2002 [http://www.diabetes.org/diabetes-statistics.jsp].

4. The Diabetes Control and Complications Trial Research Group: The effect of intensive treatment of diabetes on the development and progression of long-term complications in insulindependent diabetes mellitus. $N$ Engl J Med 1993, 329(14):977-986.

5. Giugliano D, Ceriello A, Paolisso G: Oxidative stress and diabetic vascular complications. Diabetes Care 1996, I9(3):257-267.

6. Ceriello A: New insights on oxidative stress and diabetic complications may lead to a "causal" antioxidant therapy. Diabetes Care 2003, 26(5): $1589-1596$.

7. Ceriello A, Motz E: Is oxidative stress the pathogenic mechanism underlying insulin resistance, diabetes, and cardiovascular disease? The common soil hypothesis revisited. Arterioscler Thromb Vasc Biol 2004, 24(5):816-823.

8. Turko IV, Marcondes S, Murad F: Diabetes-associated nitration of tyrosine and inactivation of succinyl-CoA:3-oxoacid CoA- 
transferase. Am J Physiol Heart Circ Physiol 200I, 28 I(6): $\mathrm{H} 2289-2294$.

9. Maritim AC, Sanders RA, Watkins JB 3rd: Diabetes, oxidative stress, and antioxidants: A review. I Biochem Mol Toxicol 2003, I7(I):24-38

10. Evans JL, Goldfine ID, Maddux BA, Grodsky GM: Oxidative stress and stress-activated signaling pathways: a unifying hypothesis of type 2 diabetes. Endocr Rev 2002, 23(5):599-622.

II. Vega-Lopez S, Devaraj S, Jialal I: Oxidative stress and antioxidant supplementation in the management of diabetic cardiovascular disease. J Investig Med 2004, 52(1):24-32.

12. Evans JL, Goldfine ID, Maddux BA, Grodsky GM: Are oxidative stress-activated signaling pathways mediators of insulin resistance and \{beta\}-cell dysfunction? Diabetes 2003, 52(I): I-8.

13. Griendling KK, FitzGerald GA: Oxidative stress and cardiovascular injury: Part I: Basic mechanisms and in vivo monitoring of ROS. Circulation 2003, 108(16): 1912-1916.

14. Griendling KK, FitzGerald GA: Oxidative stress and cardiovascular injury: Part II: animal and human studies. Circulation 2003, 1 08(I 7):2034-2040

15. Taniyama Y, Griendling KK: Reactive oxygen species in the vasculature: Molecular and cellular mechanisms. Hypertension 2003, 42(6): |075-|08|.

16. Boullier A, Bird DA, Chang MK, Dennis EA, Friedman P, Gillotre-Taylor K, Horkko S, Palinski W, Quehenberger O, Shaw P, et al.: Scavenger receptors, oxidized LDL, and atherosclerosis. Ann N $Y$ Acad Sci 200I, 947:2। 4-222

17. Liu Y, Gutterman DD: The coronary circulation in diabetes: influence of reactive oxygen species on $\mathrm{K}+$ channel-mediated vasodilation. Vascul Pharmacol 2002, 38(I):43-49.

18. Liu Y, Terata K, Chai Q, Li H, Kleinman LH, Gutterman DD: Peroxynitrite inhibits Ca2+-activated $\mathrm{K}+$ channel activity in smooth muscle of human coronary arterioles. Circ Res 2002, 91(II): 1070-1076.

19. Soriano FG, Virag L, Szabo C: Diabetic endothelial dysfunction: role of reactive oxygen and nitrogen species production and poly(ADP-ribose) polymerase activation. I Mol Med 200I, 79(8):437-448.

20. Oberg BP, McMenamin E, Lucas FL, McMonagle E, Morrow J, Ikizler TA, Himmelfarb J: Increased prevalence of oxidant stress and inflammation in patients with moderate to severe chronic kidney disease. Kidney Int 2004, 65(3): 1009-1016.

21. Guzik TJ, West NE, Black E, McDonald D, Ratnatunga C, Pillai R, Channon KM: Vascular superoxide production by $\mathbf{N A D}(\mathbf{P}) \mathbf{H}$ oxidase: association with endothelial dysfunction and clinical risk factors. Circ Res 2000, 86(9):E85-90.

22. Guzik TJ, Mussa S, Gastaldi D, Sadowski J, Ratnatunga C, Pillai R, Channon KM: Mechanisms of increased vascular superoxide production in human diabetes mellitus: role of $\mathrm{NAD}(\mathrm{P}) \mathrm{H}$ oxidase and endothelial nitric oxide synthase. Circulation 2002 105(14): 1656-1662.

23. Ceriello A, Mercuri F, Quagliaro L, Assaloni R, Motz E, Tonutti L, Taboga C: Detection of nitrotyrosine in the diabetic plasma: evidence of oxidative stress. Diabetologia 200I, 44(7):834-838.

24. Aliciguzel Y, Ozen I, Aslan M, Karayalcin U: Activities of xanthine oxidoreductase and antioxidant enzymes in different tissues of diabetic rats. J Lab Clin Med 2003, I42(3): I72-177.

25. Kitada M, Koya D, Sugimoto T, Isono M, Araki S, Kashiwagi A, Haneda $M$ : Translocation of glomerular p47phox and p67phox by protein kinase C-beta activation is required for oxidative stress in diabetic nephropathy. Diabetes 2003, 52(10):2603-26I4.

26. Etoh T, Inoguchi T, Kakimoto M, Sonoda N, Kobayashi K, Kuroda J, Sumimoto $\mathrm{H}$, Nawata $\mathrm{H}$ : Increased expression of NAD(P)H oxidase subunits, NOX4 and p22phox, in the kidney of streptozotocin-induced diabetic rats and its reversibity by interventive insulin treatment. Diabetologia 2003, 46(I0): | $428-1437$.

27. Ergul A, Schultz Johansen J, Stromhaug $C$, Harris AK, Hutchinson J, Tawfik A, Rahimi A, Rhim E, Wells B, Caldwell RW, et al: Vascular dysfunction of venous bypass conduits is mediated by reactive oxygen species in diabetes: Role of endothelin- I. J Pharmacol Exp Ther 2004, 3 I 3:70-77.

28. Amiri F, Shaw S, Wang X, Tang J, Waller JL, Eaton DC, Marrero MB: Angiotensin II activation of the JAK/STAT pathway in mesangial cells is altered by high glucose. Kidney Int 2002 61(5): $1605-1616$

29. Green K, Brand MD, Murphy MP: Prevention of mitochondrial oxidative damage as a therapeutic strategy in diabetes. Diabetes 2004, 53(SuppI I):SI I0-I I8.

30. Nishikawa T, Edelstein D, Du XL, Yamagishi S, Matsumura T, Kaneda Y, Yorek MA, Beebe D, Oates PJ, Hammes HP, et al.: Normalizing mitochondrial superoxide production blocks three pathways of hyperglycaemic damage. Nature 2000, 404(6779):787-790.

31 . Brownlee M: Biochemistry and molecular cell biology of diabetic complications. Nature 200 I, 4I 4(6865):8| 3-820.

32. Kaul N, Siveski-lliskovic N, Hill M, Khaper N, Seneviratne C, Singa PK: Probucol treatment reverses antioxidant and functional deficit in diabetic cardiomyopathy. Mol Cell Biochem 1996, 160161:283-288.

33. Hayden MR, Tyagi SC: Myocardial redox stress and remodeling in metabolic syndrome, type 2 diabetes mellitus, and congestive heart failure. Med Sci Monit 2003, 9(7):SR35-52.

34. Linke A, Adams V, Schulze PC, Erbs S, Gielen S, Fiehn E, Mobius-Winkler S, Schubert A, Schuler G, Hambrecht R: Antioxidative effects of exercise training in patients with chronic heart failure: increase in radical scavenger enzyme activity in skeletal muscle. Circulation 2005, I I I( I 4): I763-1770.

35. Cristina Polidori M, Pratico D, Savino K, Rokach J, Stahl W, Mecocci $P$ : Increased F2 isoprostane plasma levels in patients with congestive heart failure are correlated with antioxidant status and disease severity. J Card Fail 2004, 10(4):334-338.

36. Hensley K, Robinson KA, Gabbita SP, Salsman S, Floyd RA: Reactive oxygen species, cell signaling, and cell injury. Free Radic Biol Med 2000, 28(10): | 1456-1462.

37. Hensley K, Benaksas EJ, Bolli R, Comp P, Grammas P, Hamdheydari L, Mou S, Pye QN, Stoddard MF, Wallis G, et al.: New perspectives on vitamin E: gamma-tocopherol and carboxyelthylhydroxychroman metabolites in biology and medicine. Free Radic Biol Med 2004, 36(I): I-I5.

38. Hodgson JM, Watts GF, Playford DA, Burke V, Croft KD: Coenzyme Q10 improves blood pressure and glycaemic control: a controlled trial in subjects with type 2 diabetes. Eur J Clin Nutr 2002, 56( I I): II37-II42

39. Hodgson JM, Watts GF: Can coenzyme $\mathbf{Q} 10$ improve vascular function and blood pressure? Potential for effective therapeutic reduction in vascular oxidative stress. Biofactors 2003 18(I-4): 129-136.

40. Watts GF, Playford DA, Croft KD, Ward NC, Mori TA, Burke V: Coenzyme $Q(10)$ improves endothelial dysfunction of the brachial artery in Type II diabetes mellitus. Diabetologia 2002, 45(3):420-426.

4I. Heller R, Unbehaun A, Schellenberg B, Mayer B, Werner-Felmayer G Werner ER: L-ascorbic acid potentiates endothelial nitric oxide synthesis via a chemical stabilization of tetrahydrobiopterin. J Biol Chem 200I, 276(I):40-47.

42. Mekinova D, Chorvathova V, Volkovova K, Staruchova M, Grancicova $E$, Klvanoca J, Ondreicka R: Effect of intake of exogenous vitamins $C, E$ and beta-carotene on the antioxidative status in kidneys of rats with streptozotocin-induced diabetes. Nahrung 1995, 39(4):257-261.

43. Kedziora-kornatowska K, Szram S, Kornatowski T, Szadujkis-Szadurski L, Kedziora J, Bartosz G: Effect of vitamin E and vitamin C supplementation of antioxidative state and renal glomerular basement membrane thickness in diabetic kidney. Exp Nephrology 2003, 95: I34-143.

44. Cinar M, Ulker S, Alper G, Evinc A: Effect of dietary vitamin E supplementation on vascular reactivity of thoracic aorta in streptozotocin-diabetic rats. Pharmacology 200I, 62(I):56-64

45. Obrosova I, Fathallah L, Greene D: Early changes in lipid peroxidation and antioxidative defense in rat retina. Eur JPharm 2000 , 398:139-146.

46. Kocak G, Aktan F, Canbolat O, Ozogul C, Elberg S, Yildizoglu-Ari N, Karasu C: Alpha-lipoic acid treatment ameliorates metabolic parameters, blood pressure, vascular reavtivity and morphology of vessels already damaged by streptozotocin-diabetes. Diab Nutr Metab 2000, 13:308-318.

47. Rauscher F, Sanders R, Watkins Jl: Effects of coenzyme Q10 treatment on antioxidant pathways in normal and streptozotocin-induced diabetic rats. I Biochem Mol Toxicol 200I, I5:4|-46. 
48. Maritim A, Sanders R, Watkins Jl: Effects of alpha-lipoic acid on biomarkers of oxidative stress in streptozotic-induced diabetic rats. J Nutr Biochem 2003, I 4(5):288-294.

49. Brands MW, Bell TD, Gibson B: Nitric oxide may prevent hypertension early in diabetes by counteracting renal actions of superoxide. Hypertension 2004, 43(I):57-63.

50. Skyrme-Jones RA, O'Brien RC, Berry KL, Meredith IT: Vitamin E supplementation improves endothelial function in type I diabetes mellitus: a randomized, placebo-controlled study. J Am Coll Cardiol 2000, 36(I):94-102.

5I. Beckman JA, Goldfine AB, Gordon MB, Garrett LA, Keaney JF Jr, Creager MA: Oral antioxidant therapy improves endothelial function in Type I but not Type 2 diabetes mellitus. Am J Physiol 2003, 285(6): H2392-2398.

52. Gaede P, Poulsen HE, Parving HH, Pedersen O: Double-blind, randomised study of the effect of combined treatment with vitamin $C$ and $E$ on albuminuria in Type 2 diabetic patients. Diabet Med 200I, I8(9):756-760.

53. Yusuf S, Dagenais G, Pogue J, Bosch J, Sleight P: Vitamin E supplementation and cardiovascular events in high-risk patients. The Heart Outcomes Prevention Evaluation Study Investigators. N Engl J Med 2000, 342(3): I54-160.

54. Boaz M, Smetana S, Weinstein T, Matas Z, Gafter U, laina A, Knecht A, Weissgarten $Y$, Brunner D, Fainaru M, et al.: Secondary prevention with antioxidants of cardiovascular disease in endstage renal disease (SPACE): randomised placebo-controlled trial. Lancet 2000, 356(9237): $1213-1218$

55. Gaede P, Vedel P, Larsen N, Jensen GVH, Parving H-H, Pedersen O Multifactorial intervention and cardiovascular disease in patients with Type 2 diabetes. N Engl J Med 2003, 348(5):383-393.

56. Sacco M, Pellegrini F, Roncaglioni MC, Avanzini F, Tognoni G, Nicolucci A: Primary prevention of cardiovascular events with low-dose aspirin and Vitamin $E$ in Type 2 diabetic patients: Results of the Primary Prevention Project (PPP) trial. Diabetes Care 2003, 26( I 2):3264-3272.

57. Lonn EM, Yusuf S, Dzavik V, Doris Cl, Yi Q, Smith S, Moore-Cox A Bosch J, Riley WA, Teo KK: Effects of ramipril and vitamin E on atherosclerosis: The study to evaluate carotid ultrasound changes in patients treated with ramipril and vitamin $E$ (SECURE). Circulation 2001, 103(7):919-925.

58. Lonn E, Yusuf S, Hoogwerf B, Pogue J, Yi Q, Zinman B, Bosch J Dagenais G, Mann JFE, Gerstein HC: Effects of vitamin E on cardiovascular and microvascular outcomes in high-risk patients with diabetes: Results of the HOPE study and MICRO-HOPE substudy. Diabetes Care 2002, 25(I I):I919-1927.

59. Ziegler D, Hanefeld M, Ruhnau KJ, Meissner HP, Lobisch M, Schutte K, Gries FA: Treatment of symptomatic diabetic peripheral neuropathy with the anti-oxidant alpha-lipoic acid. A 3-week multicentre randomized controlled trial (ALADIN Study). Diabetologia 1995, 38(I 2): | 425- | 433.

60. Reljanovic M, Reichel G, Rett K, Lobisch M, Schuette K, Moller W, Tritschler HJ, Mehnert H: Treatment of diabetic polyneuropathy with the antioxidant thioctic acid (alpha-lipoic acid): a two year multicenter randomized double-blind placebo-controlled trial (ALADIN II). Alpha Lipoic Acid in Diabetic Neuropathy. Free Radic Res 1999, 3 I(3): I7I-179.

61. Ziegler D, Hanefeld M, Ruhnau K, Hasche H, Lobisch M, Schutte K, Kerum G, Malessa R: Treatment of symptomatic diabetic polyneuropathy with the antioxidant alpha-lipoic acid: a 7 month multicenter randomized controlled trial (ALADIN III Study). ALADIN III Study Group. Alpha-Lipoic Acid in Diabetic Neuropathy. Diabetes Care 1999, 22(8): I296-1301.

62. Ziegler D, Schatz H, Conrad F, Gries FA, Ulrich H, Reichel G: Effects of treatment with the antioxidant alpha-lipoic acid on cardiac autonomic neuropathy in NIDDM patients. A 4-month randomized controlled multicenter trial (DEKAN Study). Deutsche Kardiale Autonome Neuropathie. Diabetes Care 1997, 20(3):369-373.

63. Ametov AS, Barinov A, Dyck PJ, Hermann R, Kozlova N, Litchy WJ, Low PA, Nehrdich D, Novosadova M, O'Brien PC, et al.: The sensory symptoms of diabetic polyneuropathy are improved with \{alpha\}-Lipoic Acid: The SYDNEY Trial. Diabetes Care 2003, 26(3):770-776.

64. Ziegler D, Nowak H, Kempler P, Vargha P, Low PA: Treatment of symptomatic diabetic polyneuropathy with the antioxidant alpha-lipoic acid: a meta-analysis. Diabet Med 2004, 2 I(2): I| $|4-| 2 \mid$.

65. Dobrian AD, Davies MJ, Schriver SD, Lauterio TJ, Prewitt RL: Oxidative stress in a rat model of obesity-induced hypertension. Hypertension 200I, 37(2 Part 2):554-560.

66. Bagi Z, Koller A, Kaley G: PPARgamma activation, by reducing oxidative stress, increases NO bioavailability in coronary arterioles of mice with Type 2 diabetes. Am J Physiol 2004, 286(2): $\mathrm{H} 742-748$.

67. Fukui T, Noma T, Mizushige K, Aki Y, Kimura S, Abe Y: Dietary troglitazone decreases oxidative stress in early stage type II diabetic rats. Life Sci 2000, 66(2 I):2043-2049.

68. lida KT, Kawakami Y, Suzuki M, Shimano H, Toyoshima H, Sone H, Shimada K, Iwama Y, Watanabe Y, Mokuno H, et al.: Effect of thiazolidinediones and metformin on LDL oxidation and aortic endothelium relaxation in diabetic GK rats. Am J Physiol 2003 , 284(6): EI I 25-I I 30.

69. Wilson SH, Simari RD, Best PJ, Peterson TE, Lerman LO, Aviram M, Nath KA, Holmes DR Jr, Lerman A: Simvastatin preserves coronary endothelial function in hypercholesterolemia in the absence of lipid lowering. Arterioscler Thromb Vasc Biol 200I, 2I(I): 122-128

70. Takayama T, Wada A, Tsutamoto T, Ohnishi M, Fujii M, Isono T, Horie M: Contribution of vascular NAD(P)H oxidase to endothelial dysfunction in heart failure and the therapeutic effects of HMG-CoA reductase inhibitor. Circ J 2004, 68(II):1067-1075

71. Haendeler J, Hoffmann J, Zeiher AM, Dimmeler S: Antioxidant effects of statins via S-nitrosylation and activation of thioredoxin in endothelial cells: a novel vasculoprotective function of statins. Circulation 2004, I l 0(7):856-86 I.

72. Deakin S, Leviev I, Guernier S, James RW: Simvastatin modulates expression of the PONI gene and increases serum paraoxonase: a role for sterol regulatory element-binding protein-2. Arterioscler Thromb Vasc Biol 2003, 23(I I):2083-2089.

73. Touyz RM: Reactive oxygen species and angiotensin II signaling in vascular cells - implications in cardiovascular disease. Braz J Med Biol Res 2004, 37(8): 1263-1273.

74. Touyz RM, Schiffrin EL: Ang II-stimulated superoxide production is mediated via phospholipase $D$ in human vascular smooth muscle cells. Hypertension 1999, 34(4 Pt 2):976-982.

75. Berry C, Anderson N, Kirk AJ, Dominiczak AF, McMurray J]: Renin angiotensin system inhibition is associated with reduced free radical concentrations in arteries of patients with coronary heart disease. Heart 200I, 86(2):217-220.

76. Steinberg D, Witztum JL: Is the oxidative modification hypothesis relevant to human atherosclerosis? Do the antioxidant trials conducted to date refute the hypothesis? Circulation 2002, 105(17):2107-2III.

77. Cuzzocrea S, Riley DP, Caputi AP, Salvemini D: Antioxidant therapy: A new pharmacological approach in shock, inflammation, and ischemia/reperfusion injury. Pharmacol Rev 200I, 53(I): 135-159.

78. Szabo C, Mabley JG, Moeller SM, Shimanovich R, Pacher P, Virag L, Soriano FG, Van Duzer JH, Williams W, Salzman AL, et al.: Part I: pathogenetic role of peroxynitrite in the development of diabetes and diabetic vascular complications: studies with FPI5, a novel potent peroxynitrite decomposition catalyst. Mol Med 2002, 8( I 0):57| -580.

79. Kris-Etherton PM, Lichtenstein AH, Howard BV, Steinberg D, Witztum JL: Antioxidant vitamin supplements and cardiovascular disease. Circulation 2004, I I0(5):637-64I. 